\title{
A case of primary ovarian signet-ring cell carcinoma treated with S-1/CDDP therapy
}

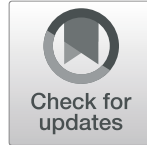

Tadahiro Shoji $1^{*}$, Ryosuke Takeshita², Tatsunori Saito², Takeshi Aida², Shunichi Sasou ${ }^{3}$ and Tsukasa Baba'

\begin{abstract}
Background: Primary ovarian signet-ring cell carcinoma is extremely rare, with only five recent case reports. Almost all reported cases of ovarian signet-ring cell carcinoma have been treated with TC therapy and none have reported regarding the use of S-1/CDDP therapy. We report a case of primary ovarian signet-ring cell carcinoma treated postoperatively with S-1/CDDP therapy.

Case presentation: We describe a 55-year-old woman diagnosed with stage IB primary ovarian signet-ring cell carcinoma that was treated with S-1/CDDP therapy. Preoperative transvaginal ultrasonography and contrastenhanced computed tomography $(C T)$ revealed a solid tumor measuring $10 \mathrm{~cm}$ in diameter in the pelvis. The tumor marker levels were as follows: CA125, 41.6 U/mL; CA19-9, <2.0 U/mL; and CEA, $2.2 \mathrm{ng} / \mathrm{mL}$. Ovarian cancer was suspected, and total abdominal hysterectomy, bilateral salpingo-oophorectomy, and omentectomy were performed. The left ovary was enlarged to greater than fist-sized, and there was a small amount of clear yellow ascites. Histological examination of the left ovary led to the diagnosis of signet-ring cell carcinoma. Histological examination of the right ovary also showed the presence of a signet-ring cell carcinoma. After surgery, upper and lower gastrointestinal endoscopy and positron-emission tomography-CT were performed to search for a possible primary lesion, but none was found. The patient was diagnosed with primary ovarian signet-ring cell carcinoma with FIGO Stage IB (PT1b, NX, M0). As postoperative adjuvant chemotherapy, S-1/CDDP therapy (S-1120 mg/day/ body $\times 14$ days, CDDP $50 \mathrm{mg} / \mathrm{m}^{2}$ day 8, q 21 days) was administered for six cycles. There was no recurrence 27 months after the initial treatment.
\end{abstract}

Conclusions: We considered S-1/CDDP therapy was effective for primary ovarian signet-ring cell carcinoma. This is the first case report of primary ovarian signet-ring cell carcinoma treated with S-1/CDDP therapy in the world.

Keywords: Ovarian cancer, Signet-ring cell carcinoma, S-1, CDDP

\section{Background}

Ovarian signet-ring cell carcinomas are mostly metastasis of cancers of digestive organs such as stomach and large bowel (so-called Krukenberg tumors) and account for approximately $2 \%$ of all ovarian cancers [1]. Primary ovarian signet-ring cell carcinoma is extremely rare, with only five recent case reports [2-6]. TC (paclitaxel/carboplatin) therapy is the standard postoperative adjuvant

\footnotetext{
* Correspondence: tshoji@iwate-med.ac.jp

1 Department of Obstetrics and Gynecology, Iwate Medical University School of Medicine, 19-1 Uchimaru, Morioka, Iwate 020-8505, Japan

Full list of author information is available at the end of the article
}

chemotherapy for epithelial ovarian cancer based on the results of GOG158 and AGO studies [7, 8]. Therefore, almost all reported cases of ovarian signet-ring cell carcinoma have been treated with TC therapy and none have reported regarding the use of S-1/CDDP therapy. Here, we report a case of primary ovarian signet-ring cell carcinoma treated postoperatively with S-1/CDDP therapy along with a literature review.

\section{Case presentation}

The patient was a 55-year-old woman, gravida 3, para 3. She had her first menstruation when she was aged 11 
years and underwent menopause at 51 years of age. She was referred to our institution with a chief complaint of irregular vaginal bleeding; however, cytological examination of the uterine cervix and endometrium showed no abnormalities. At that time, the left ovary was solid and enlarged to $6 \times 6 \mathrm{~cm}$, but because there were no subjective symptoms and her CA125 level was $23 \mathrm{U} / \mathrm{mL}$, the patient was followed up. Three months later, her left ovary had increased in size, and thus, surgery was planned. On pelvic examination, the uterus was the size of a goose egg, and a mobile mass greater than fist-sized was palpated in the cranial part of the uterus. Transvaginal ultrasonography showed a solid mass measuring $10 \times 8 \mathrm{~cm}$ in size in this region (Fig. 1). Contrastenhanced computed tomography (CT) also showed a solid mass measuring $10 \times 8 \mathrm{~cm}$ in size in the cranial part of the uterine body (Fig. 2). Routine blood test and biochemical analysis results showed no abnormalities. Regarding tumor marker levels, CA125 levels were elevated at $41.6 \mathrm{U} / \mathrm{mL}$, while CEA and CA19-9 levels were $2.2 \mathrm{ng} / \mathrm{mL}$ and $<2.0 \mathrm{U} / \mathrm{mL}$, respectively, which were within the normal ranges. Magnetic resonance imaging was not performed because the patient had claustrophobia. She was diagnosed as having a solid ovarian tumor and thus underwent laparotomy. A small amount of clear yellow ascites was observed, and the left ovary was swollen to greater than fist-sized. The uterus was enlarged to the size of a goose egg, while the right ovary was thumb-tip in size. There was no obvious dissemination in the abdominal cavity. The rapid pathological diagnosis of the left ovary was signet-ring cell carcinoma. Total abdominal hysterectomy, bilateral salpingooophorectomy, and omentectomy were performed. Intraoperatively, the digestive tract was palpated by a surgeon, with no abnormal findings. Macroscopic examination of the extracted left ovarian tumor showed a



Fig. 1 Transvaginal ultrasonography. A solid tumor margin measuring $10 \times 8 \mathrm{~cm}$ in size is visible in the cranial part of the uterus

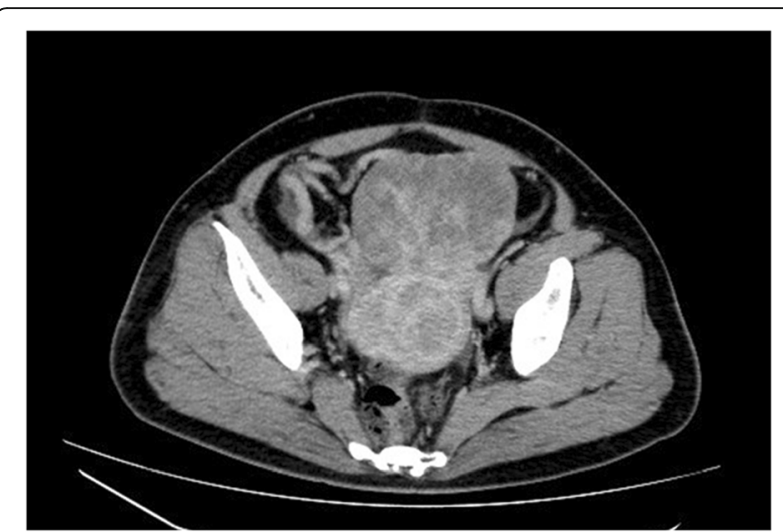

Fig. 2 Contrast-enhanced computed tomography (CT) showing an irregularly enhanced solid mass measuring $10 \times 8 \mathrm{~cm}$ in size in the cranial part of the uterine body, although the enhanced effect was lower. Lymph node enlargement suggestive of metastasis was not identified, and there were no metastases to other organs

smooth and pale yellow surface and a pale yellow and solid cut surface without mucus (Fig. 3). Cytology of the ascites was suspected to be positive. Histological examination (hematoxylin and eosin staining) showed a characteristic finding of signet-ring cell carcinoma with large and round-to-oval cells, in which the cytoplasm contained rich mucus and the nucleus was displaced toward one pole of the cell (Fig. 4). Both periodic acid-Schiff and Alcian blue staining were positive (Fig. $5 \mathrm{a}, \mathrm{b}$ ), cytokeratin (CK) 7 and CK 20 were negative (Fig. 5c, d). Based on these findings, the patient was diagnosed with signet-ring cell carcinoma. Histological examination of the right ovary also showed signet-ring cell carcinoma. As metastatic ovarian cancer was suspected, a wholebody examination was performed to search for a possible primary lesion. Upper and lower gastrointestinal endoscopy and positron-emission tomography-CT showed no



Fig. 3 Macroscopic findings of the left ovarian tumor. The surface is smooth and pale yellow, and the cut surface is solid and pale yellow without mucus 


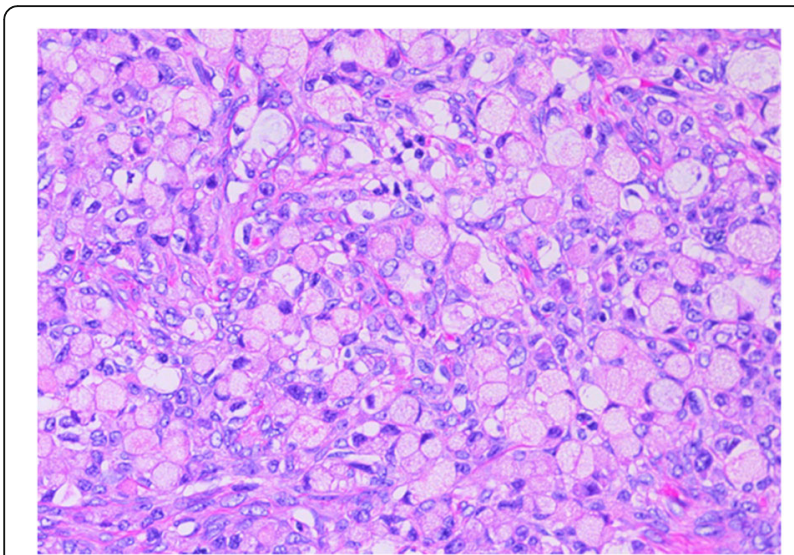

Fig. 4 Hematoxylin and eosin (HE) staining showing solitary, sporadic, diffuse, and infiltrative proliferation of large, round-to- oval cells. These cells, in which the cytoplasm contained rich mucus and the nucleus was displaced toward one pole of the cell, were diagnosed as signetring cell carcinoma

findings suggestive of a primary lesion. Based on these findings, the patient was diagnosed with primary ovarian signet-ring cell carcinoma with FIGO Stage IB (2014) (PT1b, NX, M0). After surgery, S-1/CDDP therapy (S$1120 \mathrm{mg} /$ day/body $\times 14$ days, CDDP $50 \mathrm{mg} / \mathrm{m}^{2}$ day $8, \mathrm{q}$ 21 days) was administered for six cycles after providing sufficient explanation and obtaining informed consent. The S-1/CDDP therapy for ovarian cancer was approved by the chemotherapy committee of Hachinohe Red Cross Hospital. The observed adverse events according to the Common Terminology Criteria for Adverse Events ver. 4.0 during the six cycles included grade 1 leukocytopenia, neutropenia, thrombocytopenia, liver dysfunction, nausea, vomiting, and leg edema. The six treatment cycles were completed without extending the length of the therapy or reducing the dose. Six months after the initial surgery, repeat upper and lower gastrointestinal endoscopy was performed, and no abnormalities were found. No recurrence was found 27 months after the initial surgery.

\section{Discussion}

We experienced an extremely rare case of primary ovarian signet-ring cell carcinoma. The ovarian tumor was bilateral, and metastatic ovarian cancer was suspected. Therefore, after surgery, a whole-body examination, including gastrointestinal endoscopy, was performed to search for a possible primary lesion; however, there were no findings suggestive of a primary lesion. The rapid pathological diagnosis during surgery was signet-ring cell carcinoma, which was strongly suspected as metastasis of digestive cancer. Therefore, total abdominal hysterectomy, bilateral salpingo-oophorectomy, and omentectomy were performed without lymph node dissection.

Signet-ring cell carcinoma is a subtype of adenocarcinoma in which tumor alveolar foci of various sizes, mainly composed of signet-ring cells, are present in the hyperplastic interstitial connective tissue. Signet-ring cell carcinoma commonly originates from digestive organs, especially the stomach, but may also originate from the large bowel, pancreas, and appendix [3]. In 1896, Krunkenberg reported six cases of signet-ring cell carcinoma in which the primary lesions were assumed to be in the ovary [9]. In 1986, Vijay et al. reported a varying prognosis of primary ovarian signet-ring cell carcinoma, with some showing rapid progression ranging from several
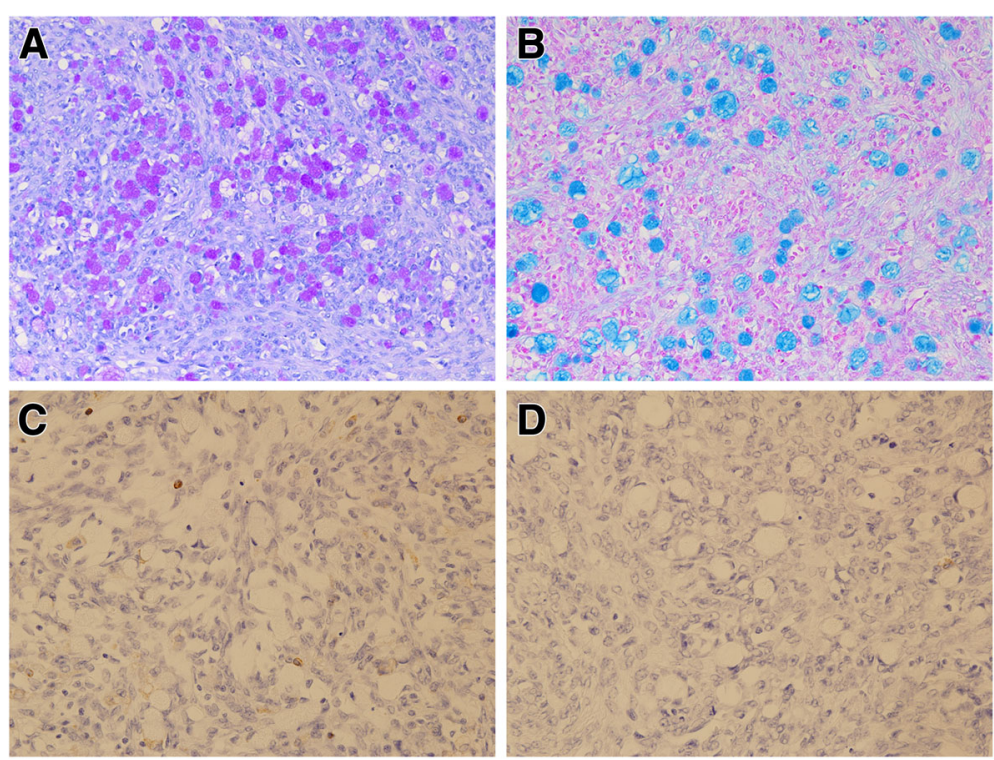

Fig. 5 Positive staining for both periodic acid-Schiff (PAS) (a) and Alcian blue (b), however cytokeratin7(c) and 20(d) showed negativity 
weeks to several months [10]. The survival rate of patients with signet-ring cell carcinoma is lower than that of patients with other histological types. The reasons for the poor prognosis are that signet-ring cell carcinoma displays a wide histological variety and is biologically malignant. Primary ovarian signet-ring cell carcinoma is infiltrative and is often accompanied by early lymph node metastasis, dissemination, and hematogenous metastasis, which are similar to the histological features of metastatic ovarian cancer. Moreover, the clinical course and prognosis of primary ovarian signet-ring cell carcinoma are similar to those of metastatic ovarian cancer.

S-1 is an oral anticancer drug that combines tegafur, a prodrug of fluorouracil, with 5-chloro-2,4-dihydropyrimidine (CDHP), and potassium oxonate at a molar ratio of 1:0.4:1. CDHP reversibly inhibits the activity of dihydropyrimidine dehydrogenase (DPD), the rate-limiting enzyme for the degradation of fluorouracil. Therefore, high concentrations of fluorouracil in serum and tumors are maintained for prolonged periods. Potassium oxonate blocks the phosphorylation of fluorouracil in the gastrointestinal tract, decreasing gastrointestinal toxic effects, the largest dose-limiting toxicity of fluorouracil [11]. S-1 is known to be active against gastric, colorectal, and pancreatic cancers [12-14]. On the other hand, cisplatin is generally believed to exert its anticancer effects by interacting with DNA, inducing programmed cell death [15].

Regarding the efficacy of initial chemotherapy for unresectable advanced/recurrent gastric cancer, the SPIRITS study compared S-1 monotherapy with S-1/ CDDP therapy and reported a significantly extended median survival in the S-1/CDDP therapy group (13 months) compared with the S-1 monotherapy group (11 months) [16]. Based on this result, S-1/CDDP therapy has been recommended as the standard treatment for unresectable advanced/recurrent gastric cancer.

We administered S-1/CDDP therapy, the standard regimen for gastric cancer described above, as postoperative adjuvant chemotherapy to this patient. The standard regimen for unresectable advanced/recurrent gastric cancer consists of oral administration of S-1 $(100 \mathrm{mg} /$ day/body) for 21 days and intravenous administration of CDDP $\left(60 \mathrm{mg} / \mathrm{m}^{2}\right)$ on day 8 , with a cycle of 5 weeks. However, the regimen used in the present case was the oral administration of S-1 (100 mg/day/body) for 14 days and intravenous administration of CDDP $\left(50 \mathrm{mg} / \mathrm{m}^{2}\right)$ on day 1 , with a cycle of 3 weeks. The reasons for this change were as follows: the efficacy and safety of the regimen for unresectable advanced/recurrent cervical cancer have been demonstrated in a clinical trial mainly involving Japanese patients [17]; we had a considerable clinical experience with this regimen; and the dose intensity is increased with a 3-week cycle. In the SPIRITS study, the incidences of grade 3 or higher leukocytopenia, neutropenia, anemia, and thrombocytopenia were $11 \%, 40 \%, 26 \%$, and $5 \%$, respectively, and the incidences of nausea and anorexia were $11 \%$ and $30 \%$, respectively [16]. In the study of S-1/CDDP therapy for unresectable advanced/recurrent cervical cancer by Aoki et al., the incidences of grade 3 or higher leukocytopenia, neutropenia, anemia, and thrombocytopenia were $32.4 \%$, $52.7 \%, 34.6 \%$, and $9.0 \%$, respectively, and the incidences of nausea and anorexia were $3.2 \%$ and $12.8 \%$, respectively [17]. In contrast, the adverse events in the present patient were minimal, with grade 1 leukocytopenia, neutropenia, thrombocytopenia, and liver dysfunction.

Table 1 shows a summary of previous studies of primary ovarian signet-ring cell carcinoma [2-6]. Some studies did not describe the disease stage or outcome,

Table 1 Previously reported cases with primary signet ring cell ovarian carcinoma

\begin{tabular}{lllllll}
\hline Author & Year & Age & Tumor size & Stage & Chemotherapy & Outcome \\
\hline Su RM ${ }^{2}$ & 2003 & 76 & $\tilde{5} \mathrm{~cm}$ & NA & NA & NED(16 months) \\
El-Safadi S $^{3}$ & 2010 & 24 & $25 \mathrm{~cm}$ & IIIC & TC & DOD(24 Months) \\
Ogawa S $^{4}$ & 2012 & 69 & $20 \mathrm{~cm}$ & IIIC & TC & DOD(2Months) \\
P JG $^{6}$ & 2014 & 38 & $18 \mathrm{~cm}$ & IC & NA & NA \\
Kim JH $^{6}$ & 2018 & 54 & $20 \mathrm{~cm}$ & NA & NA & NED(1 year) \\
Our case & & 55 & $10 \mathrm{~cm}$ & IB & S-1+CDDP & NED(27 months) \\
\hline
\end{tabular}


and chemotherapy was performed in only two studies. El-Safadi et al. reported a patient with stage IIIC primary ovarian signet-ring cell carcinoma who developed ascites immediately after completing TC therapy and had recurrence [3]. Ogawa et al. reported a patient with stage IIIC primary ovarian signet-ring cell carcinoma who died owing to the disease 2 months after receiving TC therapy [4]. We, therefore, expect that there were many patients who were diagnosed with ovarian signet-ring cell carcinoma with an unknown primary site and who were unsuccessfully treated with TC therapy. To our knowledge, this is the first reported case of primary ovarian signetring cell carcinoma that was treated with S-1/CDDP therapy in the world.

\section{Conclusions}

We reported a case of primary ovarian signet-ring cell carcinoma treated with S-1/CDDP therapy. At the time of writing this report, the patient had no recurrence 6 months after completing S-1/CDDP therapy, suggesting that the therapy was effective. We expect that S-1/CDDP therapy can be a treatment option for patients with ovarian signet-ring cell carcinoma with an unknown primary site and that this strategy may be useful in clinical practice.

\section{Authors' contributions}

TS who dealt with the case and drafted the manuscript. RT, TS and TA assisted in histo pathological report of the sample and SS and TB carried out all the documentary and article work out. All authors read and approved the final manuscript.

\section{Ethics approval and consent to participate}

This study was approved by the Ethics Committee (Institutional Review Board) of the Hachinohe Red Cross Hospital of Japan (No2019-6-1). It was conducted according to the Declaration of Helsinki for medical research. All participants received a briefing of the study and provided informed consent.

\section{Consent for publication}

Written informed consent was obtained from the patient for publication of this case report and any accompanying images.

\section{Competing interests}

The authors report no conflicts of interest in this work.

\section{Author details}

'Department of Obstetrics and Gynecology, Iwate Medical University School of Medicine, 19-1 Uchimaru, Morioka, Iwate 020-8505, Japan. ${ }^{2}$ Department of Obstetrics and Gynecology, Hachinohe Red Cross Hospital, 2 Nakaaketo, Tamonoki, Hachinohe, Aomori 039-1104, Japan. ${ }^{3}$ Department of Pathology and Laboratory, Hachinohe Red Cross Hospital, 2 Nakaaketo, Tamonoki, Hachinohe, Aomori 039-1104, Japan.

Received: 22 July 2019 Accepted: 12 March 2020

Published online: 21 March 2020

\section{References}

1. Berek JS, Natarajan S. Ovarian and fallopian tube cancer. In: Rerek JS, editor. Berek and Novak's Gynecology. 14th ed. Philadelphia: Lippincott Williams and Wilkins; 2007. p. 1457e1554.

2. Su RM, Chang KC, Chou CY. Signet-ring stromal tumor of the ovary: a case report. Int J Gynecol Cancer. 2003;13:90-3.

3. El-Safadi S, Stahl U, Tinneberg HR, Hackethal A, Muenstedt K. Primary signet ring cell mucinous ovarian carcinoma: a case report and literature review. Case Rep Oncol. 2010;3:451-7.
4. Ogawa S, Inoue S, Ogiwara S, Kitamura C, Kawarabayashi Y, Ichinoe A, et al. A case of primary signet ring cell carcinoma of the ovary. The J Fukuoka College Obstet Gynecol. 2012;36:13-6.

5. Jaya Ganesh P, Vimal Chander R, Kachana MP, Narasimhan L. Primary ovarian mucinous carcinoma with signet ring cells - report of a rare case. J Clin Diagn Res. 2014;8:FD12-3.

6. Kim JH, Cha HJ, Kim KR, Kim K. Primary ovarian signet ring cell carcinoma: a rare case report. Mol Clin Oncol. 2018;9:211-4.

7. Ozols RF, Bundy BN, Greer BE, Fowler JM, Clarke-Pearson D, Burger RA, Mannel RS, DeGeest K, Hartenbach EM, Baergen R, Gynecologic Oncology Group. Phase III trial of carboplatin and paclitaxel compared with cisplatin and paclitaxel in patients with optimally resected stage III ovarian cancer: a gynecologic oncology group study. J Clin Oncol. 2003;21:3194-200.

8. du Bois A, Lück HJ, Meier W, Adams HP, Möbus V, Costa S, et al. Arbeitsgemeinschaft Gynäkologische Onkologie ovarian Cancer study group. A randomized clinical trial of cisplatin/paclitaxel versus carboplatin/ paclitaxel as first-line treatment of ovarian cancer. J Natl Cancer Inst. 2003; 95:1320-9.

9. Krukenberg F. Uber das fibrosarcoma ovarii mucocellulare (carcinomatodes). Arch Gynecol. 1896;50:287-321.

10. Joshi W. Primary Krukenberg tumor of ovary. Review of literature and case report. Cancer. 1968;22:1199-207.

11. Shirasaka T, Shimamato $\mathrm{Y}$, Ohshimo H, Yamaguchi M, Kato T, Yonekura $\mathrm{K}$, et al. Development of a novel form of an oral 5-fluorouracil derivative (S-1) directed to the potentiation of the tumor selective cytotoxicity of 5-fluorouracil by two biochemical modulators. Anti-Cancer Drugs. 1996;7:548-57.

12. Koizumi W, Kurihara M, Nakano S, Hasegawa K. Phase II study of S-1, a novel oral derivative of 5-fluorouracil, in advanced gastric cancer. For the S-1 cooperative gastric Cancer study group. Oncology. 2000;58:191-7.

13. Ohtsu A, Baba H, Sakata Y, Mitachi Y, Horikoshi N, Sugimachi K, et al. Phase II study of S-1, a novel oral fluorophyrimidine derivative, in patients with metastatic colorectal carcinoma. S-1 cooperative colorectal carcinoma study group. Br J Cancer. 2000;83:141-5.

14. Ueno H, Okusaka T, Ikeda M, Takezako Y, Morizane C. An early phase II study of S-1 in patients with metastatic pancreatic cancer. Oncology. 2005;68:171-8.

15. Perez RP, Lewis LD, Beelen AP, Olszanski AJ, Johnston N, Rhodes $C H$, at al. Modulation of cell cycle progression in human tumors: a pharmacokinetic and tumor molecular pharmacodynamic study of cisplatin plus the Chk1 inhibitor UCN-01 (NSC 638850). Clin Cancer Res 2006; 12: 7079-7085.

16. Koizumi W, Narahara H, Hara T, Takagane A, Akiya T, Takagi M, et al. S-1 plus cisplatin versus S-1 alone for first-line treatment of advanced gastric cancer (SPIRITS trial): a phase III trial. Lancet Oncol. 2008;9:215-21.

17. Aoki Y, Ochiai K, Lim S, Aoki D, Kamiura S, Lin H, et al. Phase III study of cisplatin with or without S-1 in patients with stage IVB, recurrent, or persistent cervical cancer. Br J Cancer. 2018;119:530-7.

\section{Publisher's Note}

Springer Nature remains neutral with regard to jurisdictional claims in published maps and institutional affiliations.
Ready to submit your research? Choose BMC and benefit from:
- fast, convenient online submission
- thorough peer review by experienced researchers in your field
- rapid publication on acceptance
- support for research data, including large and complex data types
- gold Open Access which fosters wider collaboration and increased citations
- maximum visibility for your research: over $100 \mathrm{M}$ website views per year
At BMC, research is always in progress.
Learn more biomedcentral.com/submissions 